\title{
RESENHA
}

\section{Como se faz a história? Uma nova biografia de Alexandre Kojève}

\author{
FILONI, Marco. L'azione politica del filosofo. La vita e il pensiero di \\ Alexandre Kojève. Torino: Bollati Boringhieri, 2021, 346 p.
}

\author{
Judikael Castelo Branco \\ https://orcid.org/0000-0002-4551-2531 - E-mail: judikael79@hotmail.com
}

Marco Filoni volta, pouco mais de dez anos depois de publicar Il filosofo della domenica (Bollati Boringhieri, 2008), à biografia de Alexandre Kojève (1902-1968), agora com a obra L'azione politica del filosofo. Porquanto o primeiro título possa parecer mais poético, sonoro, ao mesmo tempo que respeita tanto a inspiração tirada da estética hegeliana quanto as condições de trabalho do biografado quando servia à administração do governo francês (p. 23), "o filósofo do domingo" já não reflete inteiramente o presente texto, aumentado em pelo menos 150 páginas se comparado ao anterior, e muito mais preocupado com o envolvimento de Kojève no cenário político francês durante e após a Segunda Guerra. Logo, não se trata apenas de acréscimos pontuais ao exposto no livro de 2008; não lemos, portanto, uma edição revista e ampliada, mas um novo trabalho tornado possível graças ao acesso a escritos inéditos de Kojève cedidos por Nina Kousnetzoff, neta do filósofo, à Bibliothèque nationale de France. Animado por esse novo material, Filoni retoma, com reconhecida habilidade e competência, o exercício de apreender aquela "síntese inquieta" (p. 184) que foi o intelectual do "mítico" curso sobre a Fenomenologia hegeliana e funcionário do governo francês.

Naturalmente as referências ao celebérrimo seminário sobre a Fenomenologia do espírito e ao seu extraordinário auditório abrem o texto, mas um dos mais claros méritos do trabalho de Filoni é precisamente a reconstrução da formação de Kojève, fazendo justiça ao percurso intelectual do filósofo russo, que, ao fim e ao cabo, é muito mais rico e diversificado do que a condição de intérprete original de Hegel pode sugerir.

O biografado é tomado incialmente dentro de um contexto cultural específico, a Era de prata da cultura russa, entendida como "amálgama curioso" de filosofia romântica, patriotismo local, nacionalismo religioso e utopismo arqueológico (p. 30-31). Com efeito, só considerando o 
filósofo na sua relação com o universo intelectual russo de sua origem, podemos compreender a escolha do tema de sua dissertação sobre Vladimir Solov'ëv.

É dentro dessa moldura que se formam os primeiros (e até certo ponto definitivos) interesses do jovem russo, preocupações que manifestam desde muito cedo a sua vocação ao pensamento, como demonstram as anotações em seus diários sobre a "filosofia da inexistência" e em torno da ética religiosa do cristianismo e do budismo. Além dessas questões os cadernos de Kojève trazem importantes registros acerca do direito e da morte, assim como a descrição do seu sonho com Descartes e Buda, e documentam uma preocupação que sempre o acompanhará: “Deverei depois estudar a fundo também o sistema em si: será de ajuda para cristalizar os fundamentos de minha filosofia na sua forma definitiva" (p. 79). Logo, os problemas aos quais se volta, não são fruto da leitura de Hegel, antes constituem a base para a sua interpretação da Fenomenologia, a partir da qual, como ele mesmo aspirava desde cedo, dará contornos mais precisos ao próprio pensamento.

O quadro complexivo dos interesses de Kojève entre a partida da Rússia, os estudos na Alemanha e o estabelecimento na França, resulta numa formação inimaginável para os padrões atuais (e não nos referimos apenas aos padrões brasileiros).

De um lado, essa formação se confrontava, como era comum aos intelectuais do século passado, com o tema geral da decadência cultural cuja primeira síntese mais sentida talvez tenha sido a obra de Oswald Spengle, A decadência do Ocidente, que Kojève efetivamente leu e à qual respondeu com um projeto também anotado em seus diários: ser um "filósofo da prosperidade" (p. 147).

De outro lado, a obra aponta para três temáticas específicas que definem os traços próprios do pensamento kojèviano.

Em primeiro lugar, está o seu interesse pelas civilizações orientais. Nos anos passados na Universidade de Heidelberg, por exemplo, Kojève se dedicou ao estudo de Indologia, sânscrito e mandarim, com professores como Max Walleser, Bruno Liebich e Friedrich Krause, todos reconhecidos pelo domínio da história, das línguas e das religiões do Oriente. Em parte, foi também por causa desse fascínio que o filósofo escolheu Karl Jaspers como orientador da sua dissertação sobre Solov'ëv (p. 109-118). Nesses gestos, vemos ecoar uma disposição que já estava presente nas primeiras anotações dos seus diários e que ele manterá ao longo da vida.

Em segundo lugar, o mesmo caráter excepcional se mostra nos primeiros anos franceses, quando Kojève se volta às pesquisas em física e em matemática. Filoni se preocupa em listar os físicos estudados no período, um elenco longo e que reproduzimos aqui por reconhecer a sua importância; com efeito, segundo o biógrafo, Kojève leu Poicaré, Bachelard, Whitehead, Natorp, Meyerson, Couturat, Carnot, Brunschvicg, Einstein, Heisenberg, Schrödinger, Born, Planck, Reichenbach, de Broglie, Bohr e Eddington. Os frutos desses esforços estão nos escritos Zum problem einer diskreten "Welt", de 1929, e L'idée du déterminisme dans la physique classique et dans la physique moderne, de 1932.

Por último, a temática filosófica sobre a religião, argumento que efetivamente o acompanhou desde sempre e cujos primeiros registros se encontram no diário de juventude. Nesse caso, ganha destaque o texto L'athéisme, escrito em 1931, e as relações do autor com os teólogos russos Lev Karsavin e Nicolaj Bordjaev e com figuras importantes do pensamento católico como Henri Bouillard, Gaston Fessard e Edmond Ortigues. O tema exposto em L'athéisme era tão capital para Kojève que Livio Sicchirollo - um dos orientadores de Marco Filoni nos tempos de estudo em Urbino - o definiu como "literalmente obcecado pela ideia de Deus" (p. 164).

A insistência de Filoni sobre aspectos menos comentados da obra kojèviana não quer simplesmente satisfazer curiosidades que às vezes são comuns mesmo em biografias filosó- 
ficas. Antes, nos permite compreender a moldura definitiva, entre outras coisas, para a leitura que Kojève procura para a filosofia hegeliana. Na verdade, em seu conjunto, as preocupações e os interesses que animam o filósofo giram em torno da antropologia e é em vista da compreensão do homem que ele se apropria de conceitos hegelianos fundamentais (e que a partir dele se tornaram centrais para a filosofia francesa contemporânea) como a morte, o trabalho, a luta por reconhecimento. Sobre isso, Filoni traz ainda um trecho da carta de Kojève a Tran Duc Thao, que em 1948, publicou na revista Les temps modernes um artigo analisando a Introdução à Leitura de Hegel:

O meu trabalho não tinha o caráter de um estudo histórico; eu me importava relativamente pouco com o que Hegel mesmo quis dizer no seu livro; fiz um curso de antropologia fenomenológica servindo-me dos textos hegelianos, mas dizendo apenas o que eu considerava ser a verdade, deixando de lado o que me parecia, em Hegel, um erro (p. 168).

O livro, portanto, apresenta um filósofo senhor do próprio pensamento, o que em todo caso se mostra particularmente evidente na sua abordagem da obra de Heidegger. Se o biógrafo o chama (inspirado em Eric Weil e em Jean Wahl) de "hegeliano pós-heideggeriano", é para em seguida acrescentar: "Kojève não foi nem hegeliano nem heideggeriano no sentido próprio dos termos, assim como podemos dizer que ele tenha sido tanto hegeliano quanto heideggeriano a fim de se tornar kojèviano simplesmente" (p. 304, nota 89).

A esta altura duas questões ganham especial relevância. Uma delas é desde sempre um lugar comum entre os intérpretes de Kojève, a saber, os termos definitivos da sua relação com a filosofia hegeliana. A outra, porém, só recentemente parece ganhar contornos mais precisos: qual deve ser a ação do filósofo?

No que concerne à primeira, para Kojève, e o livro deixa isso absolutamente claro, a filosofia hegeliana não apenas Ihe oferece os elementos essenciais para edificar o próprio sistema, mas, e isso parece ainda mais decisivo, ela dispõe, por sua forma de compreender a verdade, um modo radicalmente novo de pensar a natureza da filosofia e, por decorrência lógica, a tarefa do filósofo. Para Kojève, de fato, em Hegel, a filosofia se dá como projeto, ou seja, ela não toma a verdade no seu sentido corrente ou como alguns filósofos a entendem, isto é, como a adequada revelação discursiva de uma realidade, antes a verdade se dá no pensamento hegeliano como ideia ou ideal.

A outra questão aponta em uma direção clara, levantando, no entanto, uma série ainda incompleta de interrogações sobre Kojève no que diz respeito à sua atuação política. A "direção" aparece sintetizada com estes termos: "Que ação deve o filósofo realizar a fim de verificar as suas teorias? De que modo o trabalho destinado a modificar a essência das coisas deve se concretizar na ação do filósofo? Para Kojève, a resposta para essas perguntas só pode ser aquela platônica: 0 recurso à política" (p. 227-228). Como acabamos de dizer, abre-se aqui um universo de questões em torno da ação política de Kojève. Filoni não se limita a elencar tais perguntas, mas elabora com o devido cuidado algumas hipóteses no mínimo plausíveis para questões nem sempre simples. Por exemplo, sobre o "abandono" da filosofia para a entrada na carreira administrativa, o argumento é sucinto:"Muito simplesmente, Kojève se encontrava, em 1945, sem trabalho e sem renda (...) o que importava para ele de imediato era um sustento econômico" (p. 19).

Outras questões, porém, são bem mais exigentes, como a carta de Kojève a Stalin quando este último ainda não se opunha a Hitler, e a igualmente complexa relação de Kojève com o governo de Vichy.

Sobre a famosa missiva a Stalin em plena Segunda Guerra, Marco Filoni parte do testemunho de um amigo próximo de Kojève, Eugène Rubin. Para este, a carta seria, ao menos em 
parte, uma versão em russo do seminário sobre Hegel. No entanto, e eis o aspecto mais curioso da questão, duas semanas depois do envio da carta à embaixada russa, o pacto germano-soviético foi rompido, razão para Kojève deixar Paris, uma vez que o pacote poderia agora cair em mãos alemãs. Diante disso, o biógrafo levanta outra hipótese, a de que, afinal, não se tratava do curso sobre Hegel, mas de outro manuscrito, recentemente encontrado, e intitulado "Sofia. A Fenomenologia ou Ensaio de Introdução dialética à filosofia a partir da Fenomenologia de Hegel interpretada à luz do Marxismo-Leninismo-Stalinismo" (p. 197). Mas isso explica só em parte a situação, pois, se como é suposto, o desejo de Kojève era apenas assegurar que o manuscrito chegasse à Academia de Ciência de Moscou, resta ainda saber por que um tratado de filosofia seria considerado tão perigoso a ponto de fazer o autor fugir de Paris (p. 198).

Quanto à relação com Vichy, Filoni procura interpretá-la à luz de La notion de l'autorité, de 1942. Nesse texto, o filósofo propõe um anexo "embaraçante" no qual analisa o papel político e simbólico do Marechal Pétain. A questão se mostra particularmente difícil quando temos conhecimento da participação de Kojève na resistência enquanto membro do grupo Combat. A hipótese levantada por Filoni põe Kojève entre o desejo de realizar um "jogo duplo" e a vontade de entrar na lógica do poder. Aqui, vale observar as palavras de Nina Kousnetzoff ditas a Juan Pablo Lucchelli:"um dia Kojève me contou (rindo) que durante a guerra ele participava da resistência e ao mesmo tempo redigia uma Constituição para Vichy".

O livro ainda "desfaz" algumas dubiedades em torno da questão dos judeus, dubiedades criadas sobretudo por algumas passagens de La notion de l'autorité. São oportunamente citados textos do filósofo publicados em Recherches Philosophiques, nos quais ele se posiciona de forma explícita contra a ideologia do nacional-socialismo alemão (p. 217). Do mesmo modo, o livro tematiza com rigor e robusta documentação a sua participação na resistência, com o devido destaque para a propaganda antinazista assinada por Kojève e Joseph Bass - judeu francês de origem russa, fundador de um importante grupo de ação contra a deportação de judeus.

Devemos observar ainda dois aspectos que, a nosso ver, conferem um valor particular ao trabalho de Marco Filoni. Em primeiro lugar, o modo como se posiciona diante da hipótese de que Kojève tenha sido um agente da KGB. Sem grandes reservas, Filoni dedica à questão apenas uma única página, a última do livro, apontando para o excesso de suposições e para a carência de provas no que concerne a esse argumento (cf. p. 319-320, nota 20). Em segundo lugar, o livro praticamente se encerra com um capítulo muito instigante acerca do "fim da história", tema que concedeu a Kojève uma renovada notoriedade, sobretudo depois de Francis Fukuyama e O fim da história e o último homem. A nova biografia não dispensa a oportunidade de sublinhar os muitíssimos limites da interpretação de Fukuyama para a temática como também reinsere Alexandre Kojève à "tríade hegeliana" formada por ele, Alexandre Koyré e, o menos conhecido, Eric Weil (citando o excelente trabalho de Massimo Palma (2017)).

Ao fim, a obra parece entrever alguns dos próximos compromissos em torno do autor. Com efeito, não apenas cria a expectativa pela publicação do volume Sofia, mas sugere para o presente temas que merecem aprofundamento, como, por exemplo, a influência de Marcel Mauss sobre Kojève.

Como Eric Weil, amigo de Kojève, afirma em mais de uma ocasião, a filosofia é essencialmente histórica. A banalidade do enunciado não o compromete e mantém-se a exigência da sua interpretação. Aplicada ao livro que ora apreciamos, a oração implica a pergunta pelo valor de uma biografia para o estudo de filosofia. Quanto a isso, aceitando o que foi posto por Lorenz Puntel (2001, p. 349-351) de que a relação entre a filosofia e a sua história é complexa e distinta em diferentes níveis, a biografia de um filósofo seria aquele nível mais "externo" à filosofia, pois faz referência a fatores meramente históricos, que, em determinada época moldaram 
as feições de uma determinada filosofia, ou, respectivamente, moldaram a filosofia no todo de sua história. Se os dados históricos nesse nível, o biográfico, podem também ser objetos da historiografia geral, a filosofia, no entanto, não pode simplesmente negligenciá-los porquanto representam uma realidade que determina a relação entre a filosofia e a sua história. Logo, no livro de Marco Filoni, realça-se uma determinada compreensão da filosofia em um dado tempo, o de Kojève, mas não em função da mera erudição, antes como instrumentos para a reflexão sobre outro tempo histórico, o nosso, e, dentro dele, sobre a tarefa do filósofo e a natureza da filosofia.

\section{Referências}

FILONI, M. Il filosofo della demonica. La vita e il pensiero di Alexandre Kojève. Torino: Bollati Boringhieri, 2008.

PALMA, M. Foto di grupo con servo e signore. Mitologie hegeliane in Koyré, Strauss, Kojève, Bataille, Weil, Queneau. Castelvecchi: Roma, 2017.

PUNTEL, L. Sobre a complexa relação entre a filosofia e sua história. In: CIRNE LIMA, C.; ALMEIDA, C. (Orgs.). Nós e o Absoluto. São Paulo: Loyola, 2001, p. 349-372.

\section{Sobre o tradutor}

\section{Judikael Castelo Branco}

Professor da Universidade Federal do Tocantins (UFT). Doutor em Filosofia pela Universidade Federal do Ceará (UFC) e pela Université Charles de Gaulle (Lille).

Recebido em: 13/10/2021.

Aprovado em: 25/10/2021.
Received: $13 / 10 / 2021$.

Approved: 25/10/2021. 